\title{
Estimating abundance for a savanna elephant population using mark-resight methods: a case study for the Tembe Elephant Park, South Africa
}

\author{
- $\quad$ R. C. Morley ${ }^{1} \&$ \\ - R. J. van Aarde ${ }^{1}$
}

1Conservation Ecology Research Unit, Department of Zoology and Entomology, University of Pretoria, Pretoria, South Africa

Correspondence

Rudi J. van Aarde, Conservation Ecology Research Unit, Department of Zoology and Entomology, University of Pretoria, Pretoria 0002, South Africa. Tel: 27012420 2753; Fax: 270124204523

Email: rjvaarde@zoology.up.ac.za

[Figures and Tables at the bottom of the document]

\begin{abstract}
Elephants living in dense woodlands are difficult to count. Many elephant populations in Africa occur in such conditions. Estimates of these populations based on total counts, aerial counts and dung counts often lack information on precision and accuracy. We use standard mark-recapture field methods to obtain estimates of population size with associated confidence limits. We apply this approach to a closed elephant population in the Tembe Elephant Park $\left(300 \mathrm{~km}^{2}\right)$, South Africa. A registration count completed in 4 months gives a known population size. We evaluate mark-recapture models against the known population size. Individual identification profiles obtained for elephants during the registration count and mark-recapture events indicate that at least 167 elephants live in the park. We consider this value as an estimate of the minimum number alive. We include 189 sightings of bulls and 37 sightings of breeding herds in the mark-recapture modelling. Of the models we test (Petersen, Schnabel, Schumacher, Jolly-Seber, Bowden's, Poisson and negative binomial), Bowden's gives an estimate closest to the registration count. Assumptions of the model are not violated. For all models except one
\end{abstract}


(negative binomial), our estimates improve with increased sampling intensity.

Confidence intervals do not improve with increased effort except for the Schnabel model. Mark-recapture methods should be considered as reliable estimators of population size for elephants occurring in dense woodlands and forests when other methods cannot be relied on.

\section{Introduction}

Savanna elephants and fire affect vegetation (Dublin, Sinclair \& McGlade, 1990; Lock, 1993; Cumming et al., 1997; Trollope et al., 1998; van de Vijver, Foley \& Olff, 1999). Elephants confined to the Tembe Elephant Park (TEP) in South Africa are well protected, and their apparent increase may have negative consequences for sensitive vegetation types, such as sand forests, that support high levels of endemicity (Beentje, Adams \& Davis, 1994; Matthews et al., 2001). The future management of this population may involve its inclusion in a transfrontier conservation area. Through this action, traditional migratory patterns may be reinstated, thereby reducing local pressure on sensitive ecotypes within the park. Knowing the number of elephants present within the park therefore has considerable conservation implications.

The techniques used to estimate population size or densities for medium to large mammals living in wooded areas are poorly developed (Caro, 1999). For African elephants Loxodonta africana, census methods such as dung counts (Walsh \& White, 1999; Walsh et al., 2001), aerial surveys (Whitehouse, Hall-Martin \& Knight, 2001; Jachmann, 2002; Khaemba \& Stein, 2002) and calling patterns (Payne, Thompson \& Kramer, 2003) are often inadequate for small populations in dense habitats. Although aerial survey methods are well developed for open habitats (for a review see Craig, 1993), indirect methods are used for elephants occurring in dense habitats (for a review see Barnes, 1993). Whitehouse et al. (2001) showed that for small populations $(\leq 250)$, aerial surveys underestimate numbers. This problem increases with increasing population size (Whitehouse et al., 2001). Under such conditions, where the use of other methods is unviable, the use of mark-recapture methods could be evaluated (Walsh \& White, 1999). To the best of our knowledge, such a method has not been applied to elephants.

Earlier attempts to count elephants in the TEP were based on aerial surveys similar to those in use across much of Africa (i.e. Buechner et al., 1963; Laws, 1969; Eltringham, 1977; Ottichilo, 1986, 1999; St C. Gibson, Craig \& Masogo, 1998; Whitehouse et al., 2001; Jachmann, 2002). Aerial counts conducted before our study did not provide confidence limits for the park's elephant population. Our study was designed, therefore, 
to evaluate the validity of a variety of mark-recapture models (see Krebs, 1999) to estimate population size when applied to a confined population of elephants.

\section{Materials and Methods}

\section{Study site}

TEP covers an area of about $300 \mathrm{~km}^{2}$ in northern KwaZulu-Natal, South Africa $\left(27^{\circ} 01\right.$ 'S, $32^{\circ} 24^{\prime} \mathrm{E}$ ). The mean annual precipitation for the region is $800-1000 \mathrm{~mm}$ (Schulze, 1997) but this is highly variable. The mean annual temperature is $20-22^{\circ} \mathrm{C}$. The park's northern boundary forms the international border with Mozambique and an elephant-proof fence surrounds the park. Situated in the Maputaland Centre of Endemism (Beentje et al., 1994), TEP is considered to be important for the protection of regional biodiversity. There are few other protected areas in the region conserving stands of endemic-rich sand forests (van Wyk \& Smith, 2001). The confinement of elephants to TEP since 1989 is artificial and may have negative consequences for sensitive vegetation communities within the park.

\section{Methods}

One of us (R. C. M.) was an observer on an attempted total helicopter count during August 2000. Twenty-five parallel north/south orientated transects, $1 \mathrm{~km}$ apart, of between 3 and $23 \mathrm{~km}$ long, totalling c. $380 \mathrm{~km}$, were flown at $\sim 40 \mathrm{knots}$, at an altitude of $90 \mathrm{~m}$ above ground level. The count was completed in two sessions: early morning and late afternoon. The following day, elephants were observed from the same helicopter at all water bodies between 12:00 and 14:00 h. This is the hottest part of the day when elephants are expected to concentrate at water bodies.

We used a modification of Caughley's 'sequence of decisions by which a technique for estimating abundance can be chosen' (Krebs, 1999) to select mark-recapture methods to estimate population size. During our study, elephants were 'marked' through the recording of their unique markings and thereafter resighted. All methods are hereafter referred to as mark-resight methods (see Minta \& Mangel, 1989).

Our mark-resight protocol was based on individual identification using features such as ear markings and tears, tail characteristics, tusk form, wear and breakages, trunk and other scars (see Douglas-Hamilton, 1972; Croze, 1974; Jachmann, 1980; Whitehouse \& Hall-Martin, 2000; Moss, 2001). Each identifiable feature was considered a 'mark' on that individual, and all individuals carried multiple marks. These marks are considered permanent and additional marks were added during the study. Identification was aided by 
customized identification profiles that included photographs and field drawings. Elephants could be positively identified as 'marked' or 'unmarked' at the time of observation. Where models allowed, unmarked animals, once encountered and marked, were added to the 'marked' population.

For elephant bulls we conducted an initial marking programme, where bulls were identified throughout the park over 4 months, during which we 'marked' and compiled identification profiles for 52 individuals. This period of familiarization facilitated accurate individual identification. The 'marking' event was then followed by 14 resighting events, each lasting 10 days, at intervals of 7 days over a period of about 8 months.

During each of the resighting events, the entire park was surveyed from a vehicle using a road network, divided into 20 sections covered by five routes. Sessions were conducted in the morning and afternoon, avoiding the heat of midday when elephants are less active (Wyatt \& Eltringham, 1974). Resighting sessions included observations at the two main permanent water points in the Muzi Swamp and the semi-permanent pan in the south of the park. Elephants encountered during these resighting sessions, either along the routes or at waterholes, were noted as 'marked' or 'unmarked'.

We compiled identification keys for family groups using the same method as that used for bulls. During an initial marking period of 2 months, eight adult cows from different groups were 'marked', including three fitted with satellite/radio-collars as part of another study. Once herds could be recognized by the identification of a 'marked' adult cow, the remaining members were identified as described by Moss (2001). Identifying features of elephants in herds were repeatedly noted to improve estimates of herd size. The population estimate for breeding herds is based on the repetitive enumeration of individual groups and Bowden's estimator (Krebs, 1999) calculated from the sighting frequencies of the eight marked cows.

Our registration count was directed at determining the total number of elephants in the population based on individual identification profiles. The count is not reliant on a set of assumptions (Caughley \& Sinclair, 1994). As the sum of all elephants identified during the study, it gives an estimate of the animals known to be present in the research area. It is not considered a total count as new animals were recorded until the last cycle.

\section{Data analyses}

\section{Closed population estimators}

Mark-resight models for closed populations provide estimators that are robust to variation in capture probabilities, especially when the assumption of a closed population 
is valid (Kendall, 1999). The assumption of a closed population is valid for this fenced population.

We used Seber's modification of the Petersen method (Seber, 1982) for a single marking and a single recapture event to reduce potential bias in overestimating population size (Krebs, 1999). We assessed the data using the Schnabel method (an extension of the Petersen method), which makes the same assumptions as the Petersen method but in which it is easier to identify violations of these assumptions. Here marking occurs at each of the sampling times, and only two types of individuals need be identified, marked and seen once or more before and unmarked and not seen before (Krebs, 1999).

The Schumacher-Eschmeyer estimator (referred to as the Schumacher method) is a robust and useful ecological model for multiple censuses of closed populations (Seber, 1982). It allows for the non-random capture of marked and unmarked individuals (Koper $\&$ Brooks, 1998). The population estimate is obtained from the slope of the linear regression of the assumed significant relationship between the proportion of animals marked $(y)$ and those previously marked $(x)$ (Koper \& Brooks, 1998). For our study, this relationship was significant $\left(y=0.113 x+0.214, r^{2}=0.69, F_{1,12}=6.70, P<0.001\right)$.

\section{Open population estimators}

We used the Jolly-Seber model, which also allows for the estimation of parameters such as survival. This type of open population estimator is, however, of more use for longterm programmes where populations cannot be assumed as closed (Pollock et al., 1990).

\section{Model assumptions}

Generally, as models become more complex they make more assumptions. For some models, compliance with these assumptions can be tested for (see Table 1). As the equal catchability assumption is the shortcoming of all estimates that use marked animals (Krebs, 1999), a combination of open (Jolly-Seber) and closed (Schnabel) methods has been developed (Pollock, 1982).

The robust capture-recapture design allows for relatively unbiased estimates when the underlying assumptions of models are not met (Pollock, 1982; Pollock et al., 1990; Nichols, 1992) and avoids relying solely on sensitive Jolly-Seber models (Pollock et al., 1990; Krebs, 1999).

The frequency of capture analysis operates on the number of animals caught once, twice, thrice and so on over several capturing sessions (see Caughley, 1977). These data form a zero-truncated frequency distribution of captures, the missing zero class representing the unknown number of animals that were never caught. The analysis estimates the 
frequency of zero classes from the shape of the truncated distribution. Although the Poisson estimate is reliant on constant catchability, the negative binomial estimate allows for unequal sighting (Caughley, 1977).

Bowden's estimator is a frequency of capture model and is an extension of Petersen-type population estimators developed from the Minta-Mangel model (Minta \& Mangel, 1989). It is available on the program NOREMARK (White, 1996a) and MARK-RECAPTURE (Krebs, 1999). Bowden's estimator is a frequency of capture model that can be used for populations where individuals can be identified as marked. This model is designed for closed populations and relaxes the assumption that all individuals have the same resighting probability (Krebs, 1999). White (1996b) recommends the use of Bowden's estimator when there is heterogeneity of sighting probabilities. Additionally, it does not require that the entire study area be searched during a sighting period and applies even when some animals are always seen in large groups and frequently observed, whereas lone animals are rarely sighted (Bowden \& Kufeld, 1995). If mortality or emigration is independent of an animal's marked status, this model remains valid.

The assumption that the population is closed was valid as TEP is fully fenced. There was effectively no recruitment to be considered as newly born calves are easily recognized and not included in the database used for estimating population size. Five adult males died during the 2 years of the study, some of which might have been marked, and this could have reduced the number of marked animals. Bowden's estimator, however, allows for losses, provided they are independent of the mark status of the animal (Bowden $\&$ Kufeld, 1995). The assumption of equal catchability is usually violated in field studies (Pollock et al., 1990) and can be tested for in some models. To attempt to comply with this assumption, animals were sighted and marked throughout the park using all available roads and hides, thereby covering all areas utilized by elephants. Resighting locations and a satellite tracking study indicated that elephants move extensively throughout TEP and therefore could be encountered on any road or at any hide. Compliance with the assumption that marking does not affect catchability was ensured because we used a noninvasive marking method. A zero-truncated Poisson test (Krebs, 1999) showed unequal sighting probability, as is usual under field conditions (Eberhardt, 1969; Seber, 1986; Pollock et al., 1990). Bowden's estimator and Pollock's robust design relax the assumption of equal catchability to avoid this assumption. The robust design allows relatively unbiased estimates to be obtained when the assumption of equal catchability is not met (Pollock, 1982; Nichols, 1992).

The use of naturally occurring, permanent features unique to elephants that are known to persist over the long term (Douglas-Hamilton, 1972; Croze, 1974; Jachmann, 1980; 
Moss, 2001) ensured that marks were not lost. The assumption that all marks are recorded at each subsequent observation was not violated as elephants had sufficient marks to ensure that they could be identified.

\section{Analysis}

We analysed the resight data under eight different mark-resight models using the software MARK-RECAPTURE (Krebs, 1999). We used least-squares linear regression analysis (Sokal \& Rohlf, 1995) to illustrate trends in the accuracy and precision of models when effort increases. We used the small-sample unbiased Akaike information criterion $\left(\mathrm{AIC}_{\mathrm{c}}\right)$ to evaluate fit and complexity for the resight models used (see Johnson \& Omland, 2004 and references therein).

\section{Results}

\section{Population size}

A helicopter count at the onset of our study yielded a population estimate of 65 elephants. Of these, 25 were bulls and 19 were cows. Twenty-one elephants were classified as subadults or younger elephants for which sex could not be assigned from the air. The 65 elephants occurred in 20 groups (sightings). A midday waterhole count yielded 74 elephants, 29 bulls, 14 cows and 31 sub-adults or younger.

From the registration count we identified 75 bulls, 52 of these before the resighting sessions commenced. During the 14 sighting sessions, we encountered 42 of the 52 preidentified bulls and an additional 23 bulls. Five of the 52 pre-identified bulls were observed during the last four cycles of the study. Three of the 23 additional bulls were recorded in the last four cycles. We identified 92 elephants in 10 family units from observations of the eight marked cows in breeding herds and the recognition of known adult cows and their attendant young. When we combined observations of breeding herds and bulls, we obtained a 'known-to-be-alive' count of 167 elephants for TEP.

The resighting sessions yielded 65 different bulls on 189 occasions. After 14 sessions, all population estimates for bulls, except for the negative binomial $[n=87,95 \%$ confidence interval $(\mathrm{CI})=65-126]$, were lower than that obtained using the registration count [Poisson ( $n=70,95 \% \mathrm{CI}=55-86)$, Bowden's estimator $(n=67,95 \% \mathrm{CI}=60-74)$, JollySeber $(n=63,95 \%$ CI=3-123), Schumacher $(n=61,95 \%$ CI=54-69), Schnabel $(n=59$, $95 \% \mathrm{CI}=49-73)$, robust ( $n=55,95 \% \mathrm{CI}=45-79)$, Petersen $(n=38,95 \% \mathrm{CI}=27-79)$; Fig. 1a]. Only the Poisson and Bowden's models yielded estimates close to the registration count. 
On the basis of model assumptions, Bowden's estimator was the only sight-resight model suitable for estimating the population size of breeding herds. The other models require all animals to be identified as marked or unmarked upon capture (sighting). This could not be determined for all animals at every breeding herd observation. Bowden's estimator allowed population estimates when some marked animals are not identified at every sighting (Bowden \& Kufeld, 1995).

The 14 sighting events yielded marked cows on 16 occasions and all the marked cows were sighted at least once. When all post-marking sightings of breeding herds are included, breeding herds were sighted on 37 occasions. All marked cows were sighted a minimum of three times each. The estimates for breeding herds, both for sighting events and when all sightings are considered, exceed the 'known to be alive' estimate (Fig. 1b).

Bowden's estimator (all breeding herd sightings) yielded an estimate of 179 elephants for the park (Fig. 2), 4\% higher than the number of animals known to be alive for the population. For sighting sessions, Bowden's estimator under-estimated the registration count for bulls by $11 \%$ and over-estimated the breeding herd registration count by $15 \%$.

For the total population, Bowden's estimator exceeded the waterhole count by $60 \%$ and the registration count by $6.7 \%$. The helicopter survey under-counted Bowden's estimator by $65 \%$ and the registration count by $61 \%$ (Fig. 2).

\section{Influence of effort on estimates}

We used least-squares linear regression analysis to determine the influence of effort on the estimates and here consider accuracy in terms of the match of an estimate generated by a given model to the population size implied by the registration count.

For bulls the estimate generated by the negative binomial model was not affected by effort but for all the other models estimates improved with increasing effort (Fig. 3a-f).

For breeding herds, estimates did not improve with increasing effort (Fig. 4a) when the analysis was limited to data collected during resighting sessions. When all observations of breeding herds were included in the analysis, however, estimates of population size improved with increasing effort (Fig. 4b).

\section{Influence of effort on precision}

Effort only affected the width of the $95 \%$ confidence interval for the Schnabel model (Fig. 5f). For all the other models, the width of the confidence limits did not change with increased sighting effort (Fig. 5a-e). 
For breeding herds, the width of the $95 \%$ confidence interval showed no significant improvement with increased effort over time (Fig. 6a) during resighting events. However, when lumping the data for all breeding herds, the width of the $95 \%$ confidence interval decreased significantly with increasing sampling effort (number of sightings; Fig. 6b).

\section{Evaluation of resight models}

On the basis of $\mathrm{AIC}_{\mathrm{c}}$, Bowden's model $\left(\mathrm{AIC}_{\mathrm{c}}=0.87\right)$ is the most suitable when sample sizes are small. This is followed by the Schnabel $\left(\mathrm{AIC}_{\mathrm{c}}=0.10\right)$, Schumacher $\left(\mathrm{AIC}_{\mathrm{c}}=0.03\right)$ and Poisson $\left(\mathrm{AIC}_{\mathrm{c}}=0.01\right)$ models. The Jolly-Seber $\left(\mathrm{AIC}_{\mathrm{c}}=0.00\right)$ and negative binomial $\left(\mathrm{AIC}_{\mathrm{c}}=0.00\right)$ models were the least suitable of the models we evaluated.

\section{Discussion}

Capture-recapture models are often used to estimate abundances (e.g. Seber, 1982, 1986, 1992; Pollock et al., 1990; Pollock, 1991, 2000; Nichols, 1992; Krebs, 1999; and references therein). These models have been used to estimate abundance for bottlenose dolphins Tursiops truncatus (Wilson, Hammond \& Thompson, 1999), bison Bison bison (Minta \& Mangel, 1989), tigers Panthera tigris (Karanth \& Nichols, 1998), mountain sheep Ovis canadensis (Neal et al., 1993) and moose Alces alces shirasi (Bowden \& Kufeld, 1995), but have not been applied to elephants.

A zero-truncated Poisson test (see Krebs, 1999) indicated that for elephant bulls the assumption of equal catchability was violated in our study, compromising five of the eight models used (Table 1). The Jolly-Seber model proved least effective because it is specifically designed for open populations and where catchability is equal (Krebs, 1999). It yielded wide confidence intervals that did not improve with increased effort. The Petersen model was the simplest model we tested, and the low number of sightings and subsequent resightings could have compromised the model's performance, as could its sensitivity to unequal catchability (see Minta \& Mangel, 1989; Seber, 1992). The negative binomial model was the only model we used that produced an estimate higher than the registration counts. The remaining models all produced estimates lower than the known population size, but with confidence limits that were closer to the minimum number known to be present through registration counts. All the models we used yielded estimates closer to the known population than the aerial surveys. Bowden's estimator, the Schumacher method and the Schnabel method provided under-estimates of the registration count at the upper $95 \%$ confidence limit, although these were small. 
For breeding herds, our estimate of population size using Bowden's estimator exceeded the registration count, although the lower confidence limit included the known population estimate. The estimate of total population size (bulls and breeding herds) from Bowden's estimator, derived from resighting sessions, is close to the registration count and precision improved when we included all post-marking observations. This method yielded an estimate in which the $95 \%$ CIs overlapped the registration count. Our estimates of total population size from Bowden's estimator are closer to the number of elephants known to be present in the area than those yielded by aerial surveys. The Bowden's estimator allowed us to use all sightings of marked animals, which, in the case of breeding herds, improved precision (a narrower confidence limit); however, the estimate of population size was similar.

The effort expended on sighting sessions is important when designing a mark-resight study. For breeding herds, the number of observations during sighting sessions was insufficient to provide a significant improvement in the population estimate and confidence interval. With increased effort both population estimates and confidence intervals improved significantly. For bulls, all the models tested, with the exception of the negative binomial estimate, showed an increased precision with increasing effort. Only the Schnabel model showed a significant narrowing in confidence interval with increased effort over 14 sighting sessions.

Of the models tested, Bowden's estimator was the most suitable for determining population size under the conditions prevailing during our study. Bowden's estimator showed the highest probability that it was the best model of those selected ( $\mathrm{AIC}_{\mathrm{c}}$ weight) and is designed for closed populations. The model's ability to function without an assumption of equal catchability is a key attribute, and it was the only model tested that is not dependent on all marks being recorded in subsequent recapture (resighting) events. It therefore was the only model that could be applied to the breeding herd in the population. Although the precision of estimates did not improve with increased effort for the bulls, for the breeding herds the precision of the estimate did improve with increased effort (number of observations). The Petersen, Schumacher and Schnabel models are dependent on an assumption of equal catchability and could be compromised by the violation of this assumption in this study. The Petersen model was the simplest model tested and relies on a single marking event and a single recapture event. It yielded a population estimate (38 bulls) far below the registration count ( 75 bulls). The only model tested that showed an increase in the precision of the population estimate with increased effort was the Schnabel model. 
The Poisson, robust, negative binomial and Schnabel models are designed for open populations. Of these models, only the Poisson model assumes equal catchability. As expected, the least applicable model for this closed population was the Jolly-Seber model. The Jolly-Seber model is specifically designed for open populations and is highly sensitive to violations of the assumption of equal catchability. Although the estimate of population size ( 63 bulls) was within the range of other models tested (Petersen $=38$ bulls to negative binomial=87 bulls), model evaluation using $\mathrm{AIC}_{\mathrm{c}}$ showed it to be an unsuitable model. The negative binomial model was the only model that did not show an improved 'match' to the registration count with increased effort. The factors that have the largest impact on model suitability are that all animals have the same probability of sighting in the first sample, marks are not lost, marking does not affect catchability and the population is closed.

Previous estimates of population size for elephants in TEP using aerial survey methods yielded under-estimates. As a result of small population size, too few observations were obtained to allow the calculation of confidence intervals (Matthews, 2000). Aerial survey methods are relatively expensive and reliant on specialist staff. Mark-resight surveys are expensive and time intensive to initiate, but once the initial survey has been conducted subsequent estimates can be more cost effective (Minta \& Mangel, 1989). Conservation organizations in Africa have to compete for funding with other agencies and financial resources are limited; therefore, cost-efficient methods are vital.

We show that for small, closed elephant populations such as that of TEP, estimates of population size based on mark-resight estimates are valid, with confidence intervals narrower than those reported for dung counts elsewhere. Where population estimates have been determined from dung counts, investigators often failed to calculate mean decay rate or mean defecation rate; therefore, their estimates are unreliable (Nchanji \& Plumptre, 2001; Barnes, 2002). Where defecation and decay rates were determined, confidence intervals are wide (see Barnes \& Dunn, 2002).

Population counts based on the individual identification of elephants have assumed that all elephants in the populations are known (Whitehouse \& Hall-Martin, 2000; Moss, 2001) and no confidence intervals are obtained. These estimates are based on long-term studies conducted over about 30 years (Moss, 2001) and 70 years (Whitehouse \& HallMartin, 2000), and are therefore not applicable to most populations.

It has recently been proposed that the monitoring of vocal communication between elephants is a potential method of estimating population size (McComb et al., 2003; Payne et al., 2003). At present, however, these methods work over short distances and do not reliably identify individuals (McComb et al., 2003). Currently, methods based on 
vocal communication are experimental and are not yet suitable for estimating population size for elephants (see Payne et al., 2003).

Repeated mark-resight surveys can yield population trends for closed populations. A complete mark-resight survey for reserves similar in size to TEP could be completed in 8-10 days. Once established, three to four resight surveys per year would be sufficient to monitor population size and could be maintained by non-specialist technical staff. An advantage of this mark-resight method is that animals do not have to be physically captured and handled. It allows for the post hoc manipulation of data for the continuous marking of the population, and non-continuous marking, as required by Bowden's estimator (Krebs, 1999).

\section{References}

Barnes, R.F.W. (1993). Indirect methods for counting elephants in forest. Pachyderm 16, 24-30.

Barnes, R.F.W. (2002). The problem of precision and trend detection posed by small elephant populations in West Africa. Afr. J. Ecol. 40, 179-185.

Barnes, R.F.W. \& Dunn, A. (2002). The Estimating forest elephant density in Sapo National Park (Liberia) with a rainfall model. Afr. J. Ecol. 40, 159-163.

Beentje, H.J., Adams, B. \& Davis, S.D. (1994). Regional overview: Africa. In Centres of plant diversity: a guide and strategy for their conservation. Vol. 1: 101-148. Davis, S.D., Heywood, V.H. \& Hamilton, A.C. (Eds).

Gland : WWF \& IUCN.

Bowden, D.C. \& Kufeld, R.C. (1995). Generalized mark-resight population estimation applied to Colorado moose. J. Wildl. Mgmt. 59, 840-851.

Buechner, H.K., Buss, I.O., Longhurst, W.M. \& Brooks, A.C. (1963). Numbers and migration of elephants in Murchison Falls National Park, Uganda. J. Wildl. Mgmt. 27, $36-53$.

Caro, T.M. (1999). Conservation monitoring: estimating mammal densities in wooded habitats. Anim. Conserv. 2, 305-315.

Caughley, G. (1977). Analysis of vertebrate populations.

London: John Wiley \& Sons.

Caughley, G. \& Sinclair, A.E.R. (1994). Wildlife ecology \& management. 
Oxford: Blackwell Scientific Publications.

Craig, G.C. (1993). Indirect methods for counting elephants in forest. Pachyderm 16, 1520.

Croze, H. (1974). The Seronera bull problem: I. The elephants. E. Afr. Wildl. J. 12, 1-27.

Cumming, D.H.M., Fenton, M.B., Rautenbach, I.L., Taylor, R.D., Cumming, G.S., Cumming, M.S., Dunlop, J.M., Ford, A.G., Hovorka, M.D., Johnston, D.S., Kalcounis, M., Mahlangu, Z. \& Portfors, V.R. (1997). Elephants, woodlands and biodiversity in southern Africa. S. Afr. J. Sci. 93, 231-236.

Douglas-Hamilton, I. (1972). On the ecology and behaviour of the African elephant. $\mathrm{PhD}$ thesis, University of Oxford.

Dublin, H.T., Sinclair, A.R.E. \& McGlade, J. (1990). Elephants and fire as causes of multiple stable states in the Serengeti-Mara woodlands. J. Anim. Ecol. 59, 1147-1164.

Eberhardt, L.L. (1969). Population estimates from recapture frequencies. J. Wildl. Mgmt. 33, 28-39.

Eltringham, S.K. (1977). The numbers and distribution of elephant Loxodonta africana in the Rwenzori National Park and Chambura Game Reserve, Uganda. E. Afr. Wildl. J. 15, 19-39.

Jachmann, H. (1980). Population dynamics of the elephants in the Kasungu National Park, Malawi. Neth. J. Zool. 30, 622-634.

Jachmann, H. (2002). Comparison of aerial counts with ground counts for large African herbivores. J. Appl. Ecol. 39, 841-852.

Johnson, J.B. \& Omland, K.S. (2004). Model selection in ecology and evolution. Trends Ecol. Evol. 19, 101-108.

CrossRef, ISI

Karanth, K.U. \& Nichols, J.D. (1998). Estimation of tiger densities in India using photographic captures and recaptures. Ecology 79, 2852-2862.

Kendall, W.L. (1999). Robustness of closed capture-recapture methods to violations of the closure assumption. Ecology 80, 2517-2525.

Khaemba, W.M. \& Stein, A. (2002). Improved sampling of wildlife populations using airborne surveys. Wildl. Res. 29, 269-275.

Koper, N. \& Brooks, R.J. (1998). Population-size estimators and unequal catchability in painted turtles. Can. J. Zool. 76, 458-465. 
Krebs, C.J. (1999). Ecological methodology. 2nd edn. Menlo Park: Addison Wesley Longman.

Laws, R.M. (1969). The Tsavo Research Project. J. Reprod. Fertil. 6 (Suppl.), 495-531.

Lock, J.M. (1993). Vegetation change in Queen Elizabeth National Park, Uganda: 19701988. Afr. J. Ecol. 31, 106-117.

Matthews, W.S. (2000). Large herbivore population estimates for the Tembe Elephant Park. Unpublished report, KwaZulu-Natal Nature Conservation Services, Pietermaritzburg.

Matthews, W.S, van Wyk, A.E., van Rooyen, N. \& Botha, G.A. (2001). Vegetation of the Tembe Elephant Park, Maputaland, South Africa. S. Afr. J. Bot. 67, 573-594.

McComb, K., Reby, D., Baker, L., Moss, C. \& Sayialel, S. (2003). Long-distance communication of acoustic cues to social identity in African elephants. Anim. Behav. 65, $317-329$.

Minta, S. \& Mangel, M. (1989). A simple population estimate based on simulation for capture-recapture and capture-resight data. Ecology 70, 1738-1751.

Moss, C.J. (2001). The demography of an African elephant (Loxodonta africana) population in Amboseli, Kenya. J. Zool. 255, 145-156.

Nchanji, A.C. \& Plumptre, A.J. (2001). Seasonality in elephant dung decay and implications for censusing and population monitoring in south-western Cameroon. Afr. J. Ecol. 39, 24-32.

Neal, A.K., White, G.C., Gill, R.B., Reed, D.F. \& Otterman, J.H. (1993). Evaluation of mark-resight model assumptions for estimating mountain sheep numbers. J. Wildl. Mgmt. 57, 436-540.

Nichols, J.D. (1992). Capture-recapture models. Bioscience 42, 94-103.

Ottichilo, W.K. (1986). Population estimates and distribution patterns of elephants in the Tsavo ecosystem, Kenya, in 1980. Afr. J. Ecol. 24, 53-57.

Ottichilo, W.K. (1999). Comparison of sample and total counts of elephants and buffalo in the Masai Mara, Kenya. Afr. J. Ecol. 37, 435-438.

Payne, K.B., Thompson, M. \& Kramer, L. (2003). Elephant calling patterns as indicators of group size and composition: the basis for an acoustic monitoring system. Afr. J. Ecol. 41, 99-107. 
Pollock, K.H. (1982). A capture-recapture design robust to unequal probability of capture. J. Wildl. Mgmt. 46, 752-757.

Pollock, K.H. (1991). Modeling capture, recapture and removal statistics for estimation of demographic parameters for fish and wildlife populations: past, present and future. J. Am. Stat. Assoc. 86, 235-238.

Pollock, K.H. (2000). Capture-recapture models. J. Am. Stat. Assoc. 95, 293-296.

Pollock, K.H., Nichols, J.D., Brownie, C. \& Hines, J.E. (1990). Statistical inference for capture-recapture experiments. Wildl. Monogr. 107, 1-97.

Schulze, R.E. (1997). South African atlas of agrohydrology and climatology.

Pretoria: Water Research Commission.

Seber, G.A.F. (1982). The estimation of animal abundance and related parameters. 2nd edn. London: Griffin.

Seber, G.A.F. (1986). A review of estimating animal abundance. Biometrics 42, $267-$ 292.

Seber, G.A.F. (1992). A review of estimating animal abundance II. Int. Stat. Rev. 60, 129-166.

Sokal, R.R. \& Rohlf, F.J. (1995). Biometry. 3rd edn.

New York: W.H. Freeman \& Co.

St C. Gibson, D., Craig, G.C. \& Masogo, R.M. (1998). Trends of the elephant population in northern Botswana from aerial survey data. Pachyderm 25, 14-27.

Trollope, W.S.W., Trollope, L.A., Biggs, H.C., Pienaar, D. \& Potgieter, A.L.F. (1998). Long-term changes in the woody vegetation of the Kruger National Park, with special reference to the effects of elephants and fire. Koedoe 41, 103-112.

van de Vijver, C.A.D.M., Foley, C.A. \& Olff, H. (1999). Changes in the woody component of an East African savanna during 25 years. J. Trop. Ecol. 15, 545-564.

Walsh, P.D. \& White, L.J.T. (1999). What will it take to monitor forest elephant populations? Conserv. Biol. 13, 1194-1202.

Walsh, P.D., White, L.J.T., Mbina, C., Idiata, D., Mihindou, Y., Maisels, F. \& Thibault, M. (2001). Estimates of forest elephant abundance: projecting the relationship between precision and effort. J. Appl. Ecol. 38, 217-228.

White, G.C. (1996a). Noremark: population estimation from mark resighting surveys. Wildl. Soc. B 24, 50-52. 
White, G.C. (1996b). NOREMARK software reference manual, accessed 15 April 2003. http://www.colostate.edu/ gwhite/software.html.

Whitehouse, A.M. \& Hall-Martin, A.J. (2000). Elephants in Addo Elephant National Park, South Africa: reconstruction of the population's history. Oryx 34, 46-55.

Whitehouse, A.M., Hall-Martin, A.J. \& Knight, M.H. (2001). A comparison of methods used to count the elephant population of the Addo Elephant National Park, South Africa. Afr. J. Ecol. 39, 140-145.

Wilson, B., Hammond, P.S. \& Thompson, P.M. (1999). Estimating size and assessing trends in a coastal bottlenose dolphin population. Ecol. Appl. 9, 288-300.

Wyatt, J.R. \& Eltringham, S.K. (1974). The daily activity of the elephant in the Rwenzori National Park, Uganda. E. Afr. Wildl. J. 12, 273-289.

van Wyk, A.E. \& Smith, G.F. (2001). Floristic and succulent riches in southern Africa: a review of centres of endemism.

Pretoria: Umdaus Press. 


\section{Figures and Tables}

Figure 1 Population estimates for sight-resight models for (a) elephant bulls and (b) elephant breeding herds in the Tembe Elephant Park. For breeding herds only Bowden's estimator was used. Estimates for bulls are based on 14 sighting sessions. For breeding herds population size was determined from 14 sighting sessions, indicated as 'sighting sessions', and from all post-marking observations, indicated as 'all sightings'. Bars indicate population estimate; vertical lines indicate $95 \%$ confidence intervals. The dashed line denotes the number determined by registration counts.
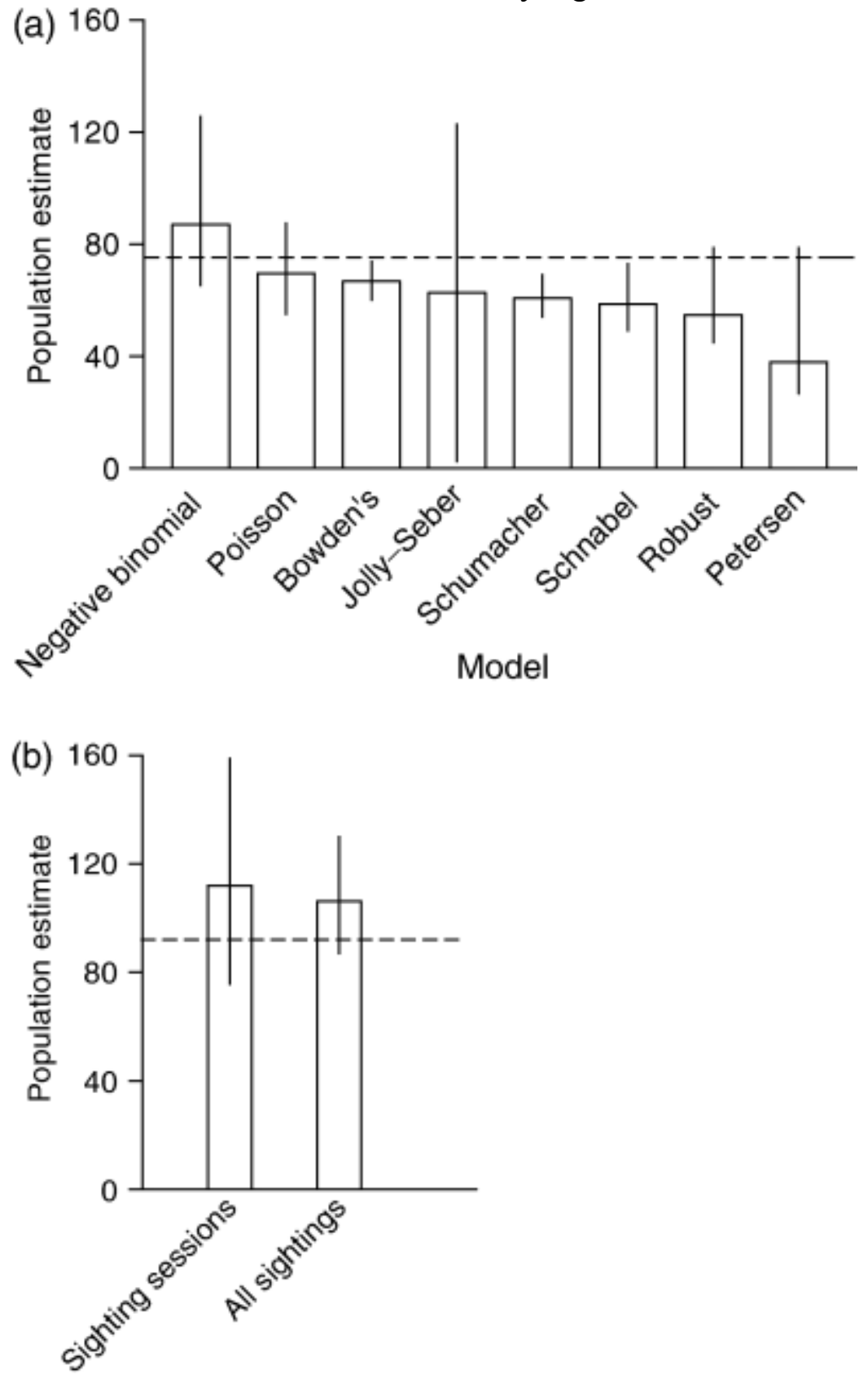
Figure 2 Comparison of population estimates determined from Bowden's estimator (sight-resight method), registration count and two aerial counting methods. Total population estimates are indicated by bars with lined fillings, animals in breeding herds by shaded bars and bulls by open bars. Vertical lines indicate $95 \%$ confidence intervals.

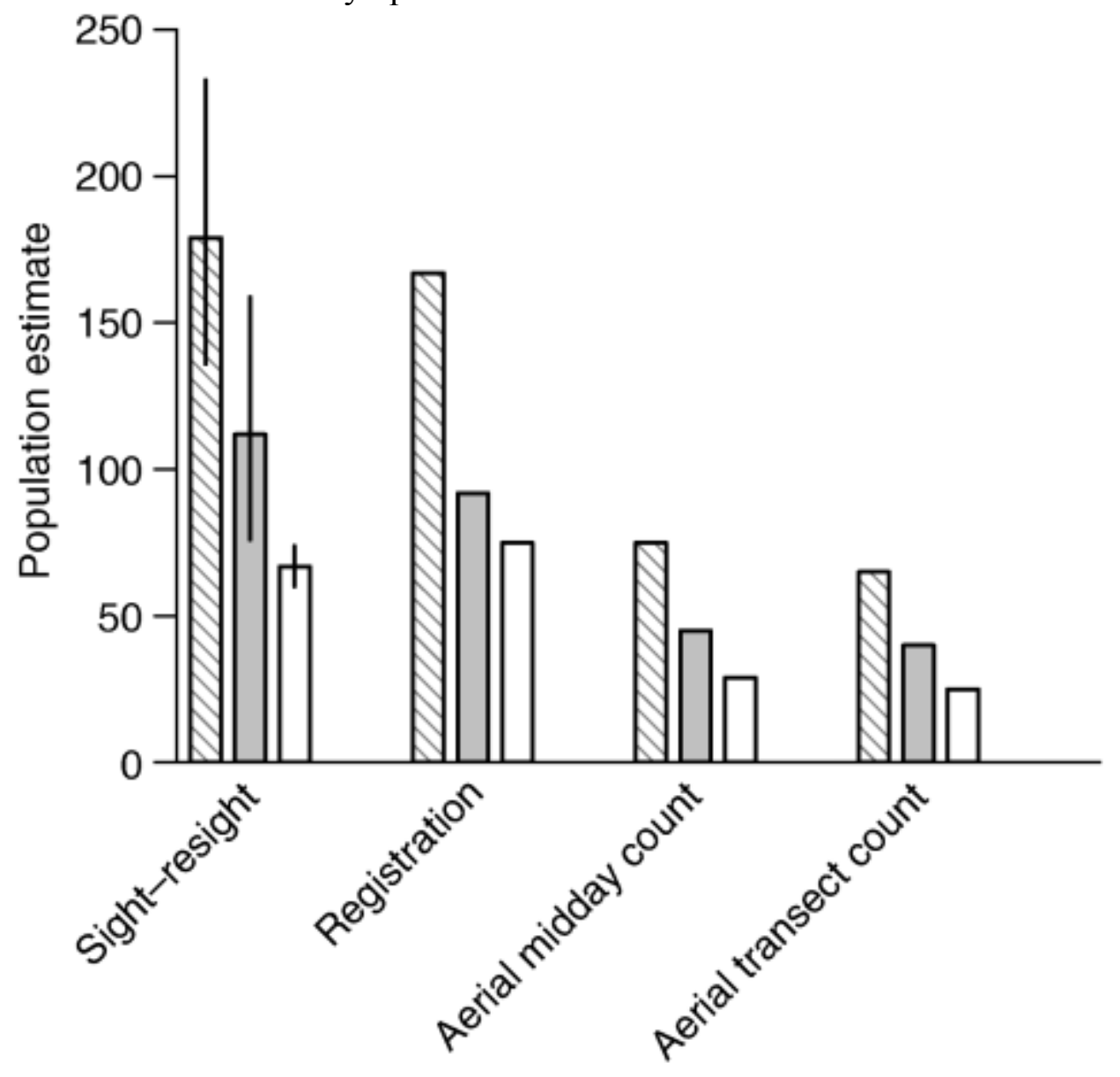


Figure 3 Influence of survey effort on population estimates for bulls from sight-resight models over 14 sighting events. Points indicate population estimates and vertical lines denote the $95 \%$ confidence intervals. Solid points indicate estimates that are within $10 \%$ of the registration count (dashed horizontal line). Solid diagonals are regression lines fitted through least-squares regression analysis and dotted lines are their $95 \%$ confidence intervals. The $F$-values test for deviation from zero of the slopes of the regression lines.
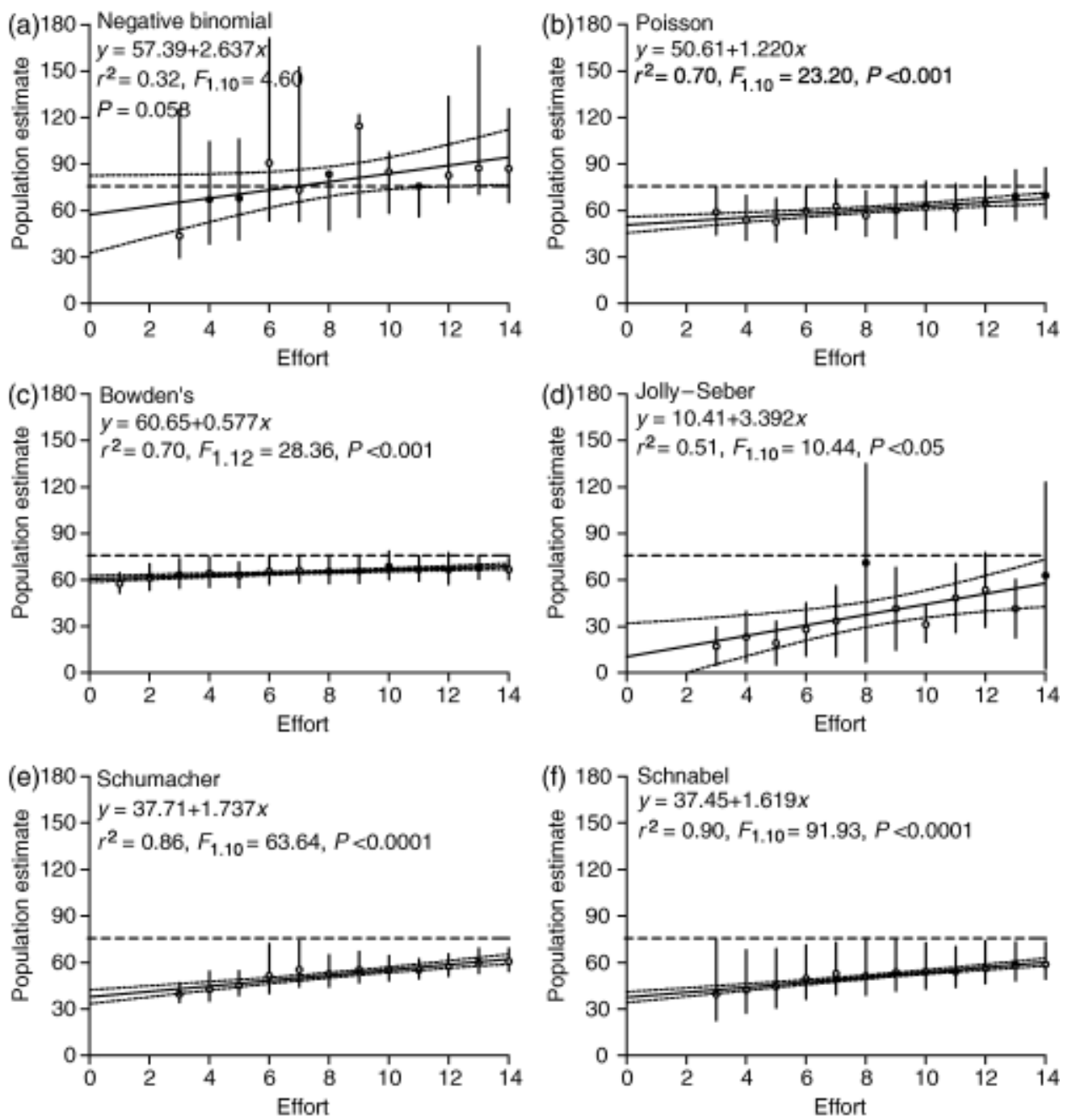
Figure 4 Influence of survey effort on population estimates for elephants in breeding herds using Bowden's estimator for (a) 14 resighting sessions on structured surveys and (b) all post-marking sightings of breeding herds. Circles indicate population estimates. Solid circles are within $10 \%$ of the registration count (dashed horizontal line). Vertical lines indicate $95 \%$ confidence intervals of the population estimates. Regression lines were fitted through least-squares regression analysis (dotted lines present the $95 \%$ confidence intervals). The $F$-values test for deviation from zero of the slopes of the regression lines.
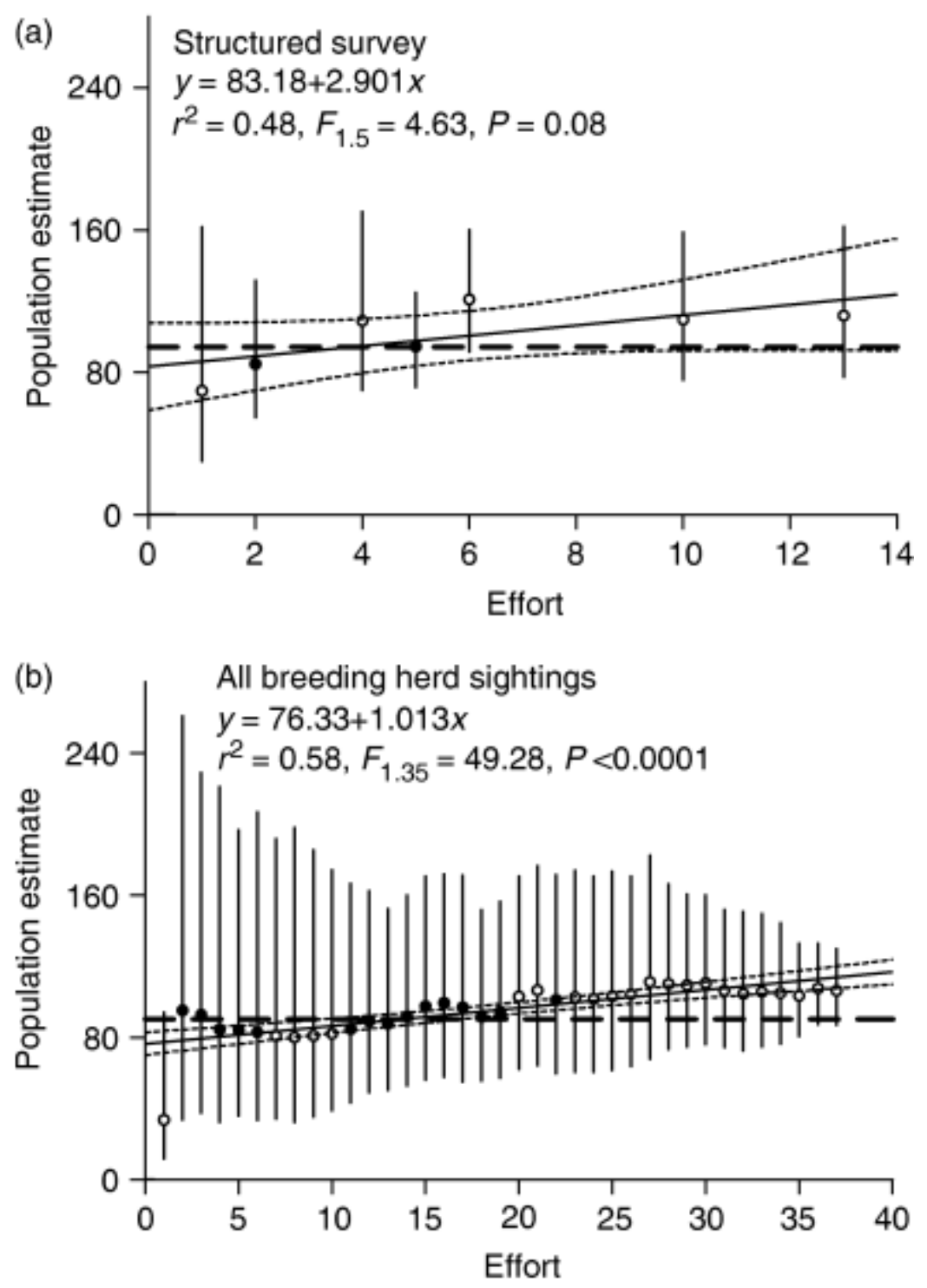
Figure 5 Influence of sampling effort on the width of the confidence limits of estimates of population size for bulls. Least-squares linear regression analyses were used to evaluate change in the $95 \%$ confidence intervals for sight-resight models as effort increased through the number of resighting sessions. Models are (a) negative binomial, (b) Poisson, (c) Bowden's, (d) Jolly-Seber, (e) Schumacher and (f) Schnabel.
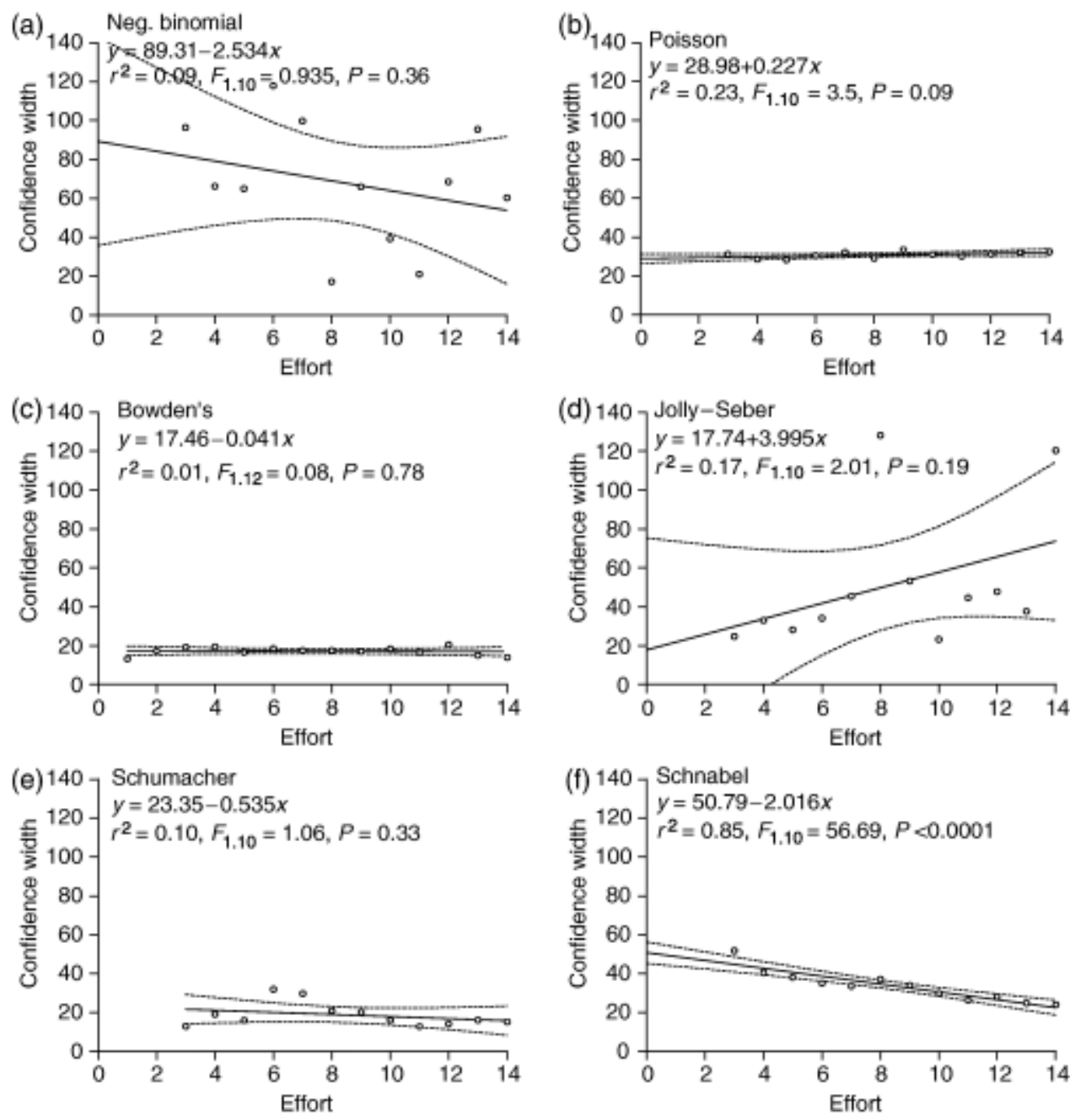
Figure 6 Influence of sampling effort on the width of the confidence limits of estimates of population size for elephants in breeding herds. Figures show least-squares linear regression analysis of $95 \%$ confidence intervals for breeding herds for Bowden's estimator, where (a) effort constitutes 14 resighting sessions and (b) effort comprises all post-marking sightings of breeding herds.
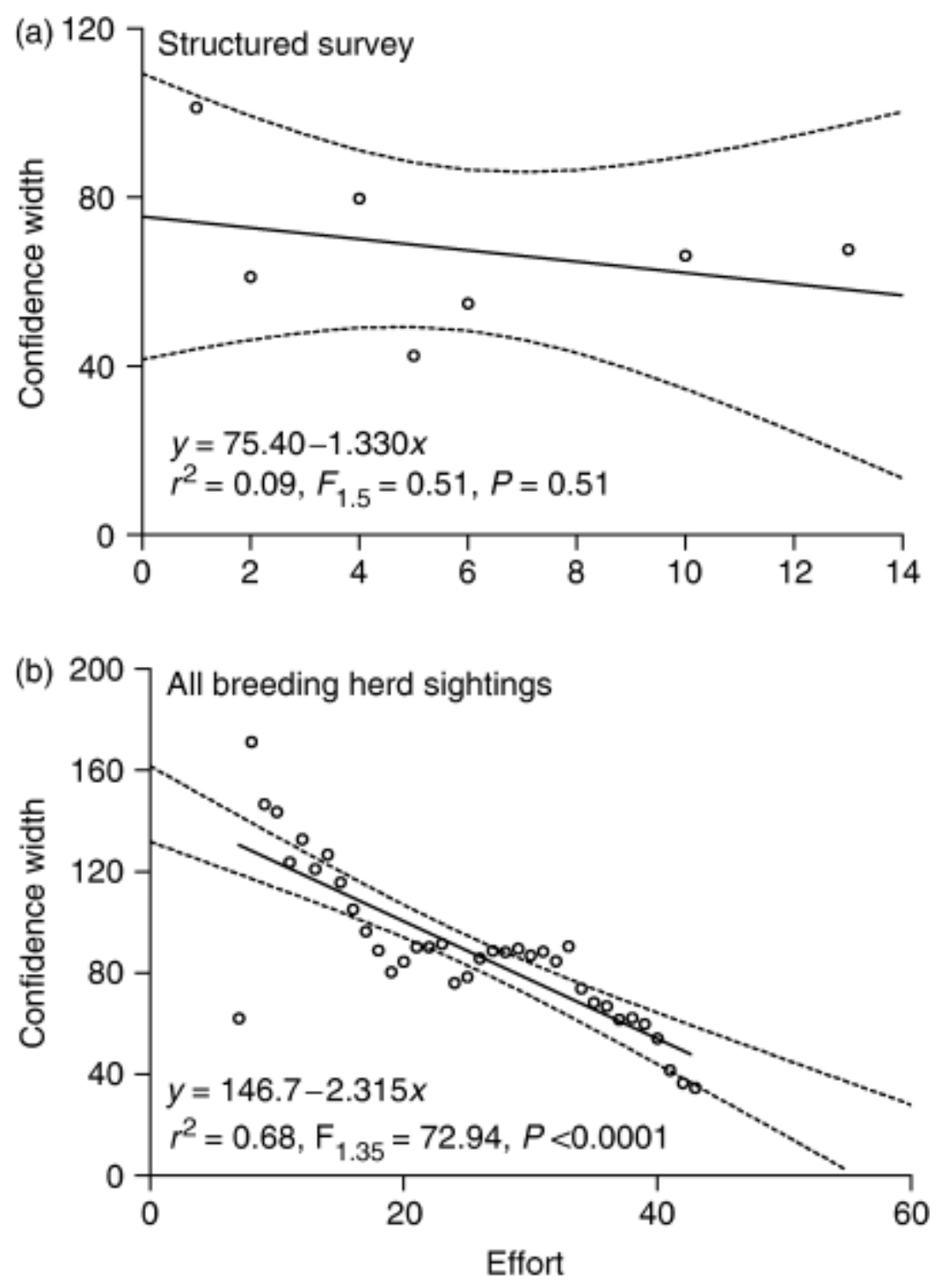
Table 1 Assumptions of the mark-recapture (resight) models used to estimate population size for the Tembe Elephant Park (see Caughley, 1977; Krebs, 1999)

\begin{tabular}{|c|c|c|c|c|c|c|c|c|}
\hline \multirow[b]{2}{*}{ Assumption } & \multicolumn{8}{|c|}{ Model } \\
\hline & Petersen & Schnabel & Schumacher & $\begin{array}{l}\text { Jolly- } \\
\text { Seber }\end{array}$ & \begin{tabular}{|l|} 
Jolly- \\
Seber \\
robust
\end{tabular} & Bowden & Poisson & $\begin{array}{l}\text { Negative } \\
\text { binomial }\end{array}$ \\
\hline $\begin{array}{l}\text { Population } \\
\text { is closed }\end{array}$ & Yes & Yes & Yes & No & No & Yes & No & No \\
\hline $\begin{array}{l}\text { All animals } \\
\text { have the } \\
\text { same } \\
\text { probability } \\
\text { of sighting } \\
\text { in the first } \\
\text { sample }\end{array}$ & Yes & Yes & Yes & Yes & Yes & Yes & No & No \\
\hline $\begin{array}{l}\text { Marking } \\
\text { does not } \\
\text { affect } \\
\text { catchability }\end{array}$ & Yes & Yes & Yes & Yes & Yes & Yes & Yes & Yes \\
\hline $\begin{array}{l}\text { Marks are } \\
\text { not lost }\end{array}$ & Yes & Yes & Yes & Yes & Yes & Yes & Yes & Yes \\
\hline $\begin{array}{l}\text { Sighting } \\
\text { probabilities } \\
\text { are equal }\end{array}$ & Yes & Yes & Yes & Yes & No & No & Yes & No \\
\hline $\begin{array}{l}\text { All marks } \\
\text { are recorded } \\
\text { in } \\
\text { subsequent } \\
\text { samples }\end{array}$ & Yes & Yes & Yes & Yes & Yes & No & Yes & Yes \\
\hline
\end{tabular}

